\title{
A Comparison of Psoriasis Severity in Pediatric Patients Treated With Methotrexate vs Biologic Agents
}

Inge M. G. J. Bronckers, MD; Amy S. Paller, MD, MSc; Dennis P. West, PhD; Irene Lara-Corrales, MD, MSc; Megha M. Tollefson, MD; Wynnis L. Tom, MD; Marcia Hogeling, MD; Leah Belazarian, MD; Claus Zachariae, MD, PhD; Emmanuel Mahé, MD, PhD; Elaine Siegfried, MD; Ulrike Blume-Peytavi, MD; Zsuzsanna Szalai, MD, PhD; Ruth Ann Vleugels, MD, MPH; Kristen Holland, MD; Ruth Murphy, MD, PhD; Lluís Puig, MD, PhD; Kelly M. Cordoro, MD; Jo Lambert, MD, PhD; Alex Alexopoulos, MD, PhD; Ulrich Mrowietz, MD, PhD; Wietske Kievit, PhD; Marieke M. B. Seyger, MD, PhD; for the Psoriasis Investigator Group, the Pediatric Dermatology Research Alliance, and the European Working Group on Pediatric Psoriasis

IMPORTANCE Few studies have compared the use of methotrexate and biologics, the most commonly used systemic medications for treatment of moderate to severe psoriasis in children.

OBJECTIVE To assess the real-world, 6-month reduction in psoriasis severity and long-term drug survival (rate and duration of adherence to a specific drug) of methotrexate vs biologics in plaque psoriasis in children.

DESIGN, SETTING, AND PARTICIPANTS A retrospective medical records review was conducted at 20 European and North American centers. Treatment response was based on site-reported Psoriasis Area and Severity Index (PASI) and/or Physician Global Assessment (PGA) scores at baseline and within the first 6 months of treatment. Participants included all 234 consecutively seen children with moderate to severe psoriasis who received at least 3 months of methotrexate or biologics from December 1, 1990, to September 16, 2014, with sufficient data for analysis. Data analysis was performed from December 14, 2015, to September 1, 2016.

MAIN OUTCOMES AND MEASURES PASI, with a range from 0 to 72 (highest score indicating severe psoriasis), and/or PGA, with a scale of $O$ (clear), 1 (minimal), 2 (mild), 3 (moderate), 4 (severe), and 5 (very severe).

RESULTS Of 234 pediatric patients (103 boys [44.0\%]; 131 girls [56.0\%]) treated with methotrexate and/or biologics, 163 patients (69.7\%) exclusively received methotrexate, 47 patients (20.1\%) exclusively received biologics, and 24 children (10.2\%) received methotrexate and biologics sequentially. Of the latter cohort, 23 children were treated initially with methotrexate. Mean (SD) age at initiation was 11.6 (3.7) years for methotrexate and 13.3 (2.9) years for biologics (73.2\% for etanercept) $(P=.002)$. Among patients evaluated by a scoring method at 6 -month follow-up, $75 \%$ or greater improvement in PASI (PASI75) was achieved in 12 of 30 patients (40.0\%) receiving methotrexate and 20 of 28 patients (71.4\%) receiving biologics, and PGA was clear/almost clear (PGA 0/1) in 41 of 115 patients (35.6\%) receiving methotrexate and 18 of 37 patients (48.6\%) receiving biologics. Achieving PASI75 and/or PGA 0/1 between baseline and 6 months was more likely with biologics than methotrexate (PASI75: odds ratio [OR], 4.56; 95\% Cl, 2.02-10.27; $P<.001$; and PGA 0/1: OR, 2.00; 95\% Cl, 0.98-4.00; $P=.06)$. Decreased mean PASI and PGA scores were associated with biologics more than with methotrexate (PASI effect, $-3.13 ; 95 \% \mathrm{Cl}$, -4.33 to $-1.94 ; P<.001$; and PGA effect, $-0.31 ; 95 \% \mathrm{Cl},-0.56$ to $-0.06 ; P=.02$ ). After 1,3 , and 5 years of use, overall drug survival rates for methotrexate were $77.5 \%, 50.3 \%$, and $35.9 \%$, and for biologics, the rates were $83.4 \%, 64.3 \%$, and $57.1 \%$, respectively. Biologics were associated with a better confounder-corrected drug survival than methotrexate (hazard ratio [HR], 2.23; 95\% Cl, 1.21-4.10; $P=.01$ ). Discontinuation owing to lack of response was comparable $(\mathrm{HR}, 1.64 ; 95 \% \mathrm{Cl}, 0.80-3.36 ; P=.18)$.

CONCLUSIONS AND RELEVANCE Methotrexate and biologics appear to be associated with improvement in pediatric psoriasis, although biologics seem to be associated with greater reduction in psoriasis severity scores and higher drug survival rates than methotrexate in the real-world setting. Additional studies directly comparing these medications should be performed for confirmation.

JAMA Dermatol. 2020;156(4):384-392. doi:10.1001/jamadermatol.2019.4835

Published online February 5, 2020.

Supplemental content

Author Affiliations: Author affiliations are listed at the end of this article.

Group Information: The members of the European Working Group on Pediatric Psoriasis Investigator Group of the Pediatric Dermatology Research Alliance are listed at the end of this article.

Corresponding Author: Inge M. G. J. Bronckers, MD, Department of Dermatology, Radboud University, Postbus 9101, 6500 HB Nijmegen René Descartesdreef 1 (route 370) Nijmegen, the Netherlands (inge.bronckers@radboudumc.nl). 
$\mathrm{P}$ soriasis is a chronic inflammatory skin disorder that affects up to $1.37 \%$ of children. Most children affected by psoriasis have plaque psoriasis. ${ }^{1,2}$ Pediatric psoriasis is often highly visible and uncomfortable, contributing to impaired quality of life and necessitating effective therapy. Although most children affected by psoriasis have mild psoriasis that is responsive to topical therapy, approximately $20 \%$ of children have moderate to severe disease that may require phototherapy or systemic therapy. ${ }^{3}$

The paucity of approved agents and direct comparative data among options complicates selection of the optimal systemic medication for individual patients. Methotrexate is the most commonly prescribed and least expensive systemic agent internationally. ${ }^{4}$ Two small, prospective studies of children with plaque psoriasis (longitudinal registry, ${ }^{5} \mathrm{n}=25$ and methotrexate arm of comparative trial vs adalimumab, ${ }^{6} \mathrm{n}=37$ ) showed that methotrexate was associated with improvement and well tolerated. Targeted therapies, including etanercept, adalimumab (tumor necrosis factor inhibitors), and ustekinumab (IL-12/23 inhibitor), have demonstrated efficacy and safety in pediatric plaque psoriasis in randomized placebo-controlled trials. ${ }^{6-10}$

The European Medicines Agency approved etanercept for plaque psoriasis in children (age 6-17 years) in 2008, ${ }^{7-9,11}$ adalimumab (age $\geq 4$ years) in $2015,{ }^{12}$ and ustekinumab (age $\geq 12$ years) in $2015 .{ }^{13,14}$ Etanercept and adalimumab have been used off-label in the United States for more than a decade, but etanercept was approved by the US Food and Drug Administration for use in children (age 4-17 years) in $2016^{15}$ and ustekinumab was approved (age $\geq 12$ years) in $2017 .{ }^{16}$ Despite the common use of methotrexate and tumor necrosis factortargeting biologics in children, to our knowledge, only methotrexate and adalimumab have been compared head-to-head and prospectively. ${ }^{6}$ To gain insight into the relative reduction in severity and real-world use of methotrexate and biologics in pediatric plaque psoriasis, experts in the Psoriasis Investigator Group of the Pediatric Dermatology Research Alliance and the European Working Group on Pediatric Psoriasis retrospectively assessed psoriasis severity scores and drug survival (rate and duration of adherence to a specific drug) of methotrexate and biologic agents.

\section{Methods}

\section{Patient Selection}

A multicenter, retrospective study in a real-world clinical practice setting was conducted by a consortium of 10 pediatric psoriasis centers in the United States and Canada and 10 centers in Europe. To compare the improvement in psoriasis severity of treatment with methotrexate vs biologics, the medical records of all patients with moderate to severe plaque psoriasis (determined by the treating physician) who used methotrexate or a biologic, either alone or sequentially (but not concurrently), before their 18th birthday for at least 3 months between December 1, 1990, and September 16, 2014, and who had at least a Minimal Core Data set (described below) recorded were included. ${ }^{4}$ Each investigator's institutional review board

\section{Key Points}

Question What is the association between use of methotrexate vs biologics and psoriasis severity and drug survival (rate and duration of adherence to a specific drug regimen) in pediatric patients with moderate to severe psoriasis?

Findings In this cohort study including 234 pediatric patients with moderate to severe psoriasis, those receiving biologics were more likely than those treated with methotrexate to achieve a Physician Global Assessment status of clear/almost clear and $75 \%$ or more improvement of the Psoriasis Area and Severity Index rating at 6 months. In addition, biologics were associated with better drug survival rates at 1,3 , and 5 years, with comparable discontinuation rates owing to lack of response.

Meaning In pediatric patients with psoriasis, treatment with biologics may be associated with a significantly greater reduction in psoriasis severity than methotrexate; nevertheless, with $35.6 \%$ of the patients achieving clear/almost clear and $40.0 \%$ reaching $75 \%$ or more improvement on the Psoriasis Area and Severity Index, methotrexate remains an effective treatment for pediatric psoriasis.

approved the protocol for this research by expedited or full review. Written informed consent or assent was waived by each investigator's institutional review board.

\section{Design and Data Management}

The Minimal Core Data set included information on patient and treatment characteristics, net treatment duration, psoriasis severity scores, and reason for drug discontinuation. ${ }^{4}$ Deidentified data from each center were transmitted to a central data coordinating center at Northwestern University, Chicago, Illinois, and organized using Research Electronic Data Capture. The first patient was reviewed on September 1, 2014, and the last patient was reviewed on July 31, 2015, with a final data lock on December 14, 2015. Data analysis was performed from December 14, 2015, to September 1, 2016.

\section{Severity Scores}

For analysis of psoriasis severity while the patients received systemic treatment, results of the Psoriasis Area and Severity Index (PASI), with a range from 0 to 72 (highest score indicating severe psoriasis), or Physician Global Assessment (PGA) had to be available within 3 months of systemic medication initiation and during at least 1 return visit at 0 to 2 months (defined as 1-month visit), 2 to 4 months (defined as 3-month visit), or 4 to 8 months (defined as 6-month visit) after treatment initiation. The Psoriasis Area and Severity Index was directly recorded from the medical record. The Physician Global Assessment was recorded from the medical record by the local investigator based on the 6-point PGA score of 0 (clear), 1 (minimal), 2 (mild), 3 (moderate), 4 (severe), and 5 (very severe). If no PGA report was available but there was an abundant clinical description of the extent and severity of the psoriasis, a central reviewer assigned a PGA score ( $<5 \%$ of patients). The percentage of missing severity score data at each specific time point was less than $10 \%$. 


\section{Drug Survival}

Drug survival was defined as the time that patients continued receiving a given drug using the technique of survival analysis with the event of note being drug discontinuation. ${ }^{17-22}$ Three events for drug survival were defined and analyzed separately: discontinuation in general, discontinuation owing to ineffectiveness (defined as inadequate effect per physician or patient assessment), and discontinuation due to adverse events (AEs). For each patient, the first methotrexate and/or biologic treatment episode was analyzed. In accordance with other drug survival studies, treatment interruption for up to 90 days was allowed within a continuous treatment episode. ${ }^{18-21}$ Patients were included in PASI/PGA and drug survival analyses until they (1) were lost to follow-up, (2) reached adulthood ( $\geq 18$ years), (3) discontinued treatment owing to an event other than the event of interest (suspected nonadherence and maximum cumulative dose or treatment duration reached), or (4) were still using the systemic agent at the time of the final data lock. ${ }^{17}$ In the drug survival analyses these data were censored (ie, only partial if no discontinuation date was recorded).

\section{Outcomes}

Outcomes were defined as the percentage of patients treated with either methotrexate or a biologic who achieved (1) PGA rating of clear or almost clear (PGA 0/1) at 6 months after initiation, (2) 75\% or greater improvement in PASI (PASI75) ${ }^{6,23}$ at 6 months, (3) PGA 0/1 and effect on mean PGA at some time during the 6 months, and (4) PASI75 (and effect on mean PASI) at some time during the 6 months (response over time). Secondary outcomes included 1-, 3-, and 5-year drug survival for methotrexate and biologics and comparison between the 2 treatment groups of overall drug survival and drug survival related to discontinuation owing to ineffectiveness.

\section{Statistical Analysis}

Demographic data were summarized as means (SDs) for continuous variables and numbers and percentages for categorical variables. Psoriasis severity data (PGA and PASI) are presented as means (SDs) and as number (percentage) of patients achieving PGA 0/1 and PASI75.

Continuous and categorical data at baseline were compared by independent-sample $t$ test and categorical data by $x^{2}$ tests for independence or Fisher exact test if applicable. Continuous and categorical treatment episode data at baseline and PGA and PASI scores at 6-month follow-up were compared by generalized estimating equations to account for dependence of measurements with different systemics used by patients who were using more than 1 systemic agent sequentially during the time of this study. The PGA and PASI responses in patients treated with methotrexate or biologics at some time during the 6-month follow-up were studied by linear mixed modeling to account for dependence of measurements with different systemics when more than 1 agent was used sequentially during the study period and for measurements at different times in 1 patient. Outcome measures were corrected for sex, age at treatment start, disease duration, follow-up time, and psoriasis severity at treatment start. The achievement of PGA 0/1 and of
PASI75 during follow-up was also analyzed by generalized estimating equation modeling to account for dependence of measurements with different systemics used by patients who were using more than 1 systemic agent sequentially during the time of this study and for measurements at different time points in 1 patient. As with linear mixed modeling above, outcome measures were corrected for sex, age at treatment start, disease duration, follow-up time, and psoriasis severity at treatment start. Only patients with complete data for these factors were selected for analyses (PGA: $\mathrm{n}=177$, PASI: $\mathrm{n}=70$ ).

Overall drug survival and drug survival related to discontinuation owing to ineffectiveness were calculated for methotrexate and biologic agents using Kaplan-Meier estimates with corresponding survival rates read from the Kaplan-Meier survival curves. Comparison of drug survival rates was analyzed using multivariable Cox regression analysis. If patient or treatment characteristics were significantly different between treatment groups, variables were included for confounder correction. Possible confounders were added as covariates to the Cox regression model. Sex, age at treatment start, and disease duration were included as fixed variables in the model, independent of significance values. Hazard ratios (HRs) with corresponding $P$ values (significant at <.05) resulting from the Cox regression model were described. All analyses were performed with SPSS, version 22.0 (IBM SPSS Inc).

\section{Results}

Study Patients

Of 446 pediatric patients in the full registry, 284 received methotrexate and/or biologics. Among these, 27 patients were excluded because of concomitant use of methotrexate and biologics and 23 were excluded owing to lack of PGA and PASI scores. In total, 210 children with plaque psoriasis were prescribed single-agent therapy with methotrexate $(n=163)$ or biologics ( $n=47$ ), and 24 children were sequentially treated with methotrexate and biologics or vice versa (eFigure in the Supplement). Of the 234 children treated with methotrexate and/or biologics, 103 were boys (44.0\%) and 131 were girls (56.0\%). Etanercept (52 [73.2\%]) and adalimumab (14 [19.7\%]) were the most frequently prescribed biologics. Only 1 patient (1.4\%) was administered infliximab, and 4 patients (5.6\%) received ustekinumab. Given the few patients treated with ustekinumab, the entire biologic cohort was used for PASI/ PGA scoring and survival analysis without further stratification.

Patient characteristics are reported in Table 1. Patients receiving methotrexate were younger at treatment onset compared with patients receiving biologics (11.6 [3.7] vs 13.3 [2.9] years; $P=.002$ ) and tended to have a shorter interval between age at diagnosis and initiation of systemic therapy (3.1 vs 4.1 years; $P=.09$ ). There was no significant difference in sex and mean body mass index and body mass index percentile between methotrexate- and biologic-treated patients. Among children receiving biologics, 52.1\% were from North America $(n=37)$ and $47.9 \%$ were from Europe $(n=34)$. The ratio of methotrexate to biologic use in North America vs Europe was comparable (North America, 3.1:1 vs Europe, 2.1:1). Based on 


\begin{tabular}{|c|c|c|c|c|c|c|}
\hline \multirow[b]{2}{*}{ Characteristic } & \multicolumn{6}{|c|}{ No. (\%) of Patients } \\
\hline & Total & $\begin{array}{l}\text { Methotrexate } \\
\text { Only }\end{array}$ & $\begin{array}{l}\text { Biologic } \\
\text { Agent Only }\end{array}$ & $P$ Value $^{\mathrm{c}}$ & $\begin{array}{l}\text { Sequential Methotrexate } \\
\text { and Biologic Agent }{ }^{\mathrm{d}} \\
\text { or Vice Versa }\end{array}$ & $P$ Value $^{\mathrm{e}}$ \\
\hline Patients, No. (\%) & 234 & $163(69.7)$ & $47(20.1)$ & & $24(10.2)$ & NA \\
\hline \multicolumn{6}{|l|}{ Continent } & NA \\
\hline North America & $148(63.0)$ & $111(68.1)$ & $33(70.2)$ & \multirow{2}{*}{.78} & \multicolumn{2}{|l|}{$4(16.7)$} \\
\hline Europe & $87(37.0)$ & $52(31.9)$ & $14(29.8)$ & & \multicolumn{2}{|l|}{$20(83.3)$} \\
\hline \multicolumn{6}{|l|}{ Sex } & NA \\
\hline Male & $103(44.0)$ & $68(41.7)$ & $17(36.2)$ & \multirow{2}{*}{.50} & \multicolumn{2}{|l|}{$18(75.0)$} \\
\hline Female & $131(56.0)$ & $95(58.3)$ & $30(63.8)$ & & \multicolumn{2}{|l|}{$6(25.0)$} \\
\hline \multicolumn{6}{|l|}{ Race } & NA \\
\hline White & $149(63.7)$ & $96(58.9)$ & $32(68.1)$ & \multirow{4}{*}{.94} & \multicolumn{2}{|l|}{$20(83.3)$} \\
\hline Black or African American & $8(3.4)$ & $7(4.3)$ & $1(2.1)$ & & \multicolumn{2}{|l|}{0} \\
\hline Asian & $6(2.6)$ & $4(2.5)$ & $1(2.1)$ & & \multicolumn{2}{|l|}{$1(4.2)$} \\
\hline Unknown or not reported & $71(30.3)$ & $56(34.4)$ & $13(27.7)$ & & \multicolumn{2}{|l|}{$3(12.5)$} \\
\hline \multicolumn{6}{|l|}{ Ethnicity } & NA \\
\hline Not Hispanic or Latino & $104(44.4)$ & 70 (42.9) & $21(44.7)$ & \multirow{3}{*}{.49} & \multicolumn{2}{|l|}{$13(54.2)$} \\
\hline Hispanic or Latino & $27(11.5)$ & $16(9.8)$ & $8(17.0)$ & & \multicolumn{2}{|l|}{$2(8.3)$} \\
\hline Unknown or not reported & $103(44.0)$ & $77(47.2)$ & $18(38.3)$ & & \multicolumn{2}{|l|}{$9(37.5)$} \\
\hline BMI category $(n=102)$ & $(n=89)$ & $(n=85)$ & $(n=17)$ & & $(n=12)$ & NA \\
\hline Underweight & $6(5.7)$ & $6(8.1)$ & 0 & \multirow{4}{*}{.12} & \multicolumn{2}{|l|}{0} \\
\hline Normal weight & $52(49.5)$ & $36(48.6)$ & $8(44.4)$ & & \multicolumn{2}{|l|}{$7(58.3)$} \\
\hline Overweight & $18(17.1)$ & $11(14.9)$ & $7(38.9)$ & & \multicolumn{2}{|l|}{0} \\
\hline Obesity & $29(27.6)$ & $21(28.4)$ & $3(16.7)$ & & \multicolumn{2}{|l|}{$5(41.7)$} \\
\hline BMI percentile, mean (SD) & $66.5(32.2)$ & $66.3(32.5)$ & $76.6(26.1)$ & .22 & $67.0(31.3)$ & NA \\
\hline BMI, mean (SD) & $21.4(6.1)$ & $21.4(6.0)$ & $24.6(7.5)$ & .06 & $22.3(7.4)$ & NA \\
\hline Age at diagnosis, mean (SD), y & $8.7(3.8)$ & $8.6(3.8)$ & $9.1(3.9)$ & .46 & $8.0(3.5)$ & NA \\
\hline Age at start of systemic therapy, mean (SD), y & $N A^{f}$ & $11.6(3.7)$ & $13.3(2.9)$ & .002 & $\begin{array}{l}\text { Methotrexate: } 12.0(2.9) \\
\text { Biologic: } 13.3(3.1)\end{array}$ & .002 \\
\hline Disease duration, mean (SD), y & $N A^{f}$ & $3.1(3.4)$ & $4.1(3.3)$ & .09 & $\begin{array}{l}\text { Methotrexate: } 4.0(3.2) \\
\text { Biologic: } 5.3(3.2)\end{array}$ & .001 \\
\hline Treatment duration, mean (SD), y & $N A^{f}$ & $1.6(1.8)$ & $1.8(1.6)$ & .39 & $\begin{array}{l}\text { Methotrexate: } 1.1(1.0) \\
\text { Biologic: } 1.4(1.4)\end{array}$ & .46 \\
\hline $\begin{array}{l}\text { Naive for systemic medication/previously used } \\
\text { systemic medication }\end{array}$ & $N A^{f}$ & $159(97.5)$ & $45(95.7)$ & .62 & $\begin{array}{l}\text { Methotrexate: } 20(83.3) \\
\text { Biologic: } 1(4.2)\end{array}$ & .001 \\
\hline $\begin{array}{l}\text { Naive for biologic agents/previously used } \\
\text { biologic agents }{ }^{9}\end{array}$ & $N A^{f}$ & $163(100.0)$ & NA & NA & $\begin{array}{l}\text { Methotrexate: } 23(95.8) \\
\text { Biologic: NA }\end{array}$ & NA \\
\hline $\begin{array}{l}\text { Naive for methotrexate/previously used } \\
\text { methotrexate }^{\mathrm{d}}\end{array}$ & $N A^{f}$ & NA & $47(100.0)$ & NA & $\begin{array}{l}\text { Methotrexate: NA } \\
\text { Biologic: } 1(4.2)\end{array}$ & NA \\
\hline \multicolumn{3}{|c|}{$\begin{array}{l}\text { Abbreviations: BMI, body mass index (calculated as weight in kilograms divided } \\
\text { by height in meters squared); NA, not applicable. }\end{array}$} & $\begin{array}{l}\text { d Etanercept was } \mathrm{t} \\
\text { by adalimumab ( }\end{array}$ & $\begin{array}{l}\text { nost freque } \\
2.5 \%]) \text { and }\end{array}$ & $\begin{array}{l}\text { ly prescribed biologic (20 [8 } \\
\text { tekinumab }(14.2 \%]) \text {. }\end{array}$ & 3\%]) followe \\
\hline $\begin{array}{l}\text { a Patients could have been previously treated wit } \\
\text { agents (except methotrexate). However, patien } \\
\text { time with a single systemic medication. }\end{array}$ & $\begin{array}{l}\text { onventional sy } \\
\text { vere treated at }\end{array}$ & $\begin{array}{l}\text { temic } \\
\text { any one }\end{array}$ & $\begin{array}{l}\text { e Continuous and } \mathrm{c} \\
\text { equations to acce } \\
\text { systemics used b }\end{array}$ & $\begin{array}{l}\text { gorical data } \\
\text { t for depen } \\
\text { patient. }\end{array}$ & $\begin{array}{l}\text { ere compared by generalize } \\
\text { nce of measurements with d }\end{array}$ & $\begin{array}{l}\text { estimating } \\
\text { erent }\end{array}$ \\
\hline $\begin{array}{l}\text { b Etanercept was the most frequently prescribed } \\
\text { by adalimumab ( } 11 \text { [23.4\%]), ustekinumab (3 [6 }\end{array}$ & $\begin{array}{l}\text { logic (32 [68.19 } \\
\text { b]), and inflixim }\end{array}$ & $\begin{array}{l}\text { ]) followed } \\
\text { b (1 [2.1\%]). }\end{array}$ & $\begin{array}{l}{ }^{\mathrm{f}} \text { Mean could not } \mathrm{b} \\
\text { treated sequentic }\end{array}$ & $\begin{array}{l}\text { alculated fo } \\
\text { with metho }\end{array}$ & $\begin{array}{l}\text { he total group because } 24 \mathrm{p} \\
\text { exate and biologic agents or }\end{array}$ & $\begin{array}{l}\text { ents were } \\
\text { ce versa. }\end{array}$ \\
\hline $\begin{array}{l}\text { ' Comparison of patients who received single-ag } \\
\text { or a biologic. Continuous data were compared } t \\
\text { and categorical data by } \chi^{2} \text { tests for independen } \\
\text { applicable. }\end{array}$ & $\begin{array}{l}\text { therapy with } m \\
\text { רdependent-sal } \\
\text { or Fisher exact }\end{array}$ & $\begin{array}{l}\text { ethotrexate } \\
\text { nples } t \text { test } \\
\text { est if }\end{array}$ & $\begin{array}{l}\mathrm{g} \text { Of } 24 \text { patients, } 2 \\
\text { from biologics to }\end{array}$ & $\begin{array}{l}\text { vitched fron } \\
\text { thotrexate. }\end{array}$ & nethotrexate to biologics an & switched \\
\hline
\end{tabular}

episodes of drug use (counting patients with sequential methotrexate and biologic use as 2 episodes), methotrexate was firstline systemic therapy for psoriasis in $95.7 \%$ of methotrexatetreated patients $(n=179)$, whereas a biologic was first-line in $64.8 \%(n=46)$ of biologic-treated patients (eTable 1 in the Supplement). Twenty-four children (10.2\%) used both methotrexate and biologics sequentially, 23 of whom (95.8\%) switched from methotrexate to biologics (Table 1). All children were included in the comparison of psoriasis severity while receiving treatment. For those who used single-agent therapy with methotrexate $(n=163)$, the mean (SD) start dosage was $0.28(0.14) \mathrm{mg} / \mathrm{kg}$ per week and the mean maximum dosage was $0.36(0.15) \mathrm{mg} / \mathrm{kg}$ per week. For patients who were sequentially treated with methotrexate and a biologic or vice 


\begin{tabular}{|c|c|c|c|c|c|c|}
\hline \multirow[b]{2}{*}{ Severity Measure $^{c}$} & \multirow[b]{2}{*}{ Medication } & \multirow[b]{2}{*}{$\begin{array}{l}\text { No. of Treatment } \\
\text { Episodes }\end{array}$} & \multicolumn{2}{|l|}{ Outcomes } & \multirow[t]{2}{*}{$\triangle \mathrm{PGA} / \triangle \mathrm{PASI}$} & \multirow[b]{2}{*}{$P$ Value $^{\mathrm{d}}$} \\
\hline & & & Baseline & $\begin{array}{l}\text { 6-mo } \\
\text { Follow-up }\end{array}$ & & \\
\hline Patients, №. (\%) & & & & & NA & \\
\hline \multirow[t]{2}{*}{ PGA 0/1 } & Methotrexate & 115 & 0 & $41(35.6)$ & & \multirow{2}{*}{.15} \\
\hline & Biologic $^{e}$ & 37 & 0 & $18(48.6)$ & & \\
\hline \multirow[t]{2}{*}{ PASI75 } & Methotrexate & 30 & NA & $12(40.0)$ & & \multirow{2}{*}{.02} \\
\hline & Biologic $^{f}$ & 28 & NA & $20(71.4)$ & & \\
\hline \multicolumn{7}{|c|}{ Severity scores, mean (SD) } \\
\hline \multirow[t]{2}{*}{ PGA } & Methotrexate & 115 & $3.6(0.7)$ & $1.9(1.1)$ & $1.6(1.2)$ & \multirow{2}{*}{.32} \\
\hline & Biologic $^{e}$ & 37 & $3.6(0.8)$ & $1.8(1.2)$ & $1.9(1.2)$ & \\
\hline \multirow[t]{2}{*}{ PASI } & Methotrexate & 30 & $11.8(6.2)$ & $5.0(5.1)$ & $6.8(4.7)$ & \multirow{2}{*}{.02} \\
\hline & Biologic $^{f}$ & 28 & $13.7(7.7)$ & $3.1(2.4)$ & $10.6(7.4)$ & \\
\hline
\end{tabular}

Abbreviations: PASI, Psoriasis Area and Severity Index; PASI75, 75\% or greater improvement in PASI; PGA, Physician Global Assessment.

a Patients could have been previously treated with conventional systemic agents except methotrexate. However, patients were treated at any 1 time with a single systemic medication.

b Participating sites provided PASI and/or PGA scores at medication initiation and during at least 1 follow-up visit. Patient numbers are therefore not identical in both groups.

c PASI scores were determined using a range of 0 to 72 , with the highest score indicating severe psoriasis, and/or PGA scores were determined using a scale of 0 (clear), 1 (minimal), 2 (mild), 3 (moderate), 4 (severe), and 5 (very severe)

at medication initiation.

${ }^{\mathrm{d}}$ Continuous ( $\triangle \mathrm{PGA}$ and $\triangle \mathrm{PASI}$ ) and categorical (PGA O/1 and PASI75) data were compared with generalized estimating equations to account for dependence of measurements with different systemic agents used at different times during the study period. The probability of methotrexate or biologic was estimated as a function of the characteristic.

e Etanercept was the most frequently prescribed biologic (27 [73.0\%]) followed by adalimumab (7 [18.9\%]), ustekinumab (2 [5.4\%]), and infliximab (1 [2.7\%]).

${ }^{f}$ Etanercept was the most frequently prescribed biologic (21 [75.0\%]) followed by adalimumab (3 [10.7\%]) and ustekinumab (4 [14.3\%]).

versa ( $\mathrm{n}=24)$, the mean starting dosage was $0.24(0.10) \mathrm{mg} / \mathrm{kg}$ per week and the mean maximum dosage was $0.29(0.11) \mathrm{mg} / \mathrm{kg}$ per week. Although numbers were small, there was a disproportional representation of obese children among those who switched from methotrexate to biologics ( 5 of 12 patients [41.7\%]). More than 90\% of biologic use occurred after European Medicines Agency approval of etanercept and publication of the pivotal pediatric study in January $2008^{7}$ (the drug was commercially available in the United States starting in 2004) and during the last quarter of the study period (December 2008 to September 2014) (eTable 2 in the Supplement).

\section{Psoriasis Severity}

Without correction for confounders, at 6 months, PASI75 was achieved in 12 of 30 patients $(40.0 \%)$ receiving methotrexate and 20 of 28 patients $(71.4 \%)$ receiving biologics $(P=.02)$. In addition, achievement of PGA 0/1 tended to be higher with biologics (18 of 37 patients [48.6\%]) than methotrexate (41 of 115 patients [35.6\%]) but did not reach statistical significance $(P=.15)$ (Table 2). After correction for potential confounders (psoriasis severity at baseline, follow-up, sex, age at treatment start, and disease duration), achievement of PGA 0/1 and PASI75 from baseline through 6 months was more likely with biologics vs methotrexate (Table 3 and eTable 3 in the Supplement) (PGA 0/1: odds ratio [OR], 2.00; 95\% CI, 0.98-4.00; $P=.06$; PASI75: OR, 4.56; 95\% CI, 2.02-10.27; $P<.001)$. Reduction in mean PGA and PASI scores with biologics compared with methotrexate was also greater throughout the 6-month treatment (Table 3 and eTable 4 in the Supplement) (PGA effect, -0.31 ; 95\% CI, -0.56 to $-0.06 ; P=.02$; PASI effect, -3.13 ; 95\% CI, -4.33 to $-1.94 ; P<.001)$. These data sug- gest that a greater reduction in psoriasis severity with biologics occurs within 6 months after initiation.

At data lock, 66 of 187 patients (35.3\%) had discontinued methotrexate treatment, most frequently for ineffectiveness (36 [19.3\%]), occurrence of AEs (22 [11.8\%]), and treatment nonadherence reported by the patient and/or family (7 [3.7\%]). Sixteen of 71 patients (22.5\%) discontinued a biologic primarily because of ineffectiveness (11 [15.5\%]) or AE occurrence (4 [5.6\%]).

\section{Drug Survival}

For drug survival, 265 treatment episodes were included (methotrexate, $\mathrm{n}=187$; biologics, $\mathrm{n}=71$ ). As depicted in the Figure, A, 77.5\% of patients continued to receive methotrexate after 1 year, $50.3 \%$ after 3 years, and $35.9 \%$ after 5 years. The median overall survival duration for methotrexate was 36.0 months (95\% CI, 23.07-49.53). The median drug survival related to discontinuation owing to ineffectiveness was 73.6 months (95\% CI, 32.19-115.04). The overall drug survival for biologics was $83.4 \%$ after 1 year, $64.3 \%$ after 3 years, and $57.1 \%$ after 5 years (Figure, A). Median drug survival times for biologic agents could not be estimated because more than $50 \%$ of the patients were still receiving the drug at the end of the study.

Biologic agents had a longer confounder-corrected drug survival than methotrexate (HR, 2.23; 95\% CI, 1.21-4.10; $P=.01$ ) (eTable 5 in the Supplement). Confounder-corrected drug survival owing to ineffectiveness was comparable between groups (HR, 1.64; 95\% CI, 0.80-3.36; $P=.18$ ), whereas discontinuation due to AEs occurred more frequently with methotrexate compared with biologics (HR, 4.67; 95\% CI, 1.08- 20.26; 
Table 3. Psoriasis Severity Through 6-Month Follow-up by Treatment Group for PGA and PASI

\begin{tabular}{|c|c|c|c|c|c|c|c|c|}
\hline \multirow[b]{2}{*}{ Treatment } & \multicolumn{2}{|c|}{ PGA 0/1 $1^{a, b, c}$} & \multicolumn{2}{|c|}{ PASI75 a,b,c } & \multicolumn{2}{|c|}{ PGA Score ${ }^{a, b, d}$} & \multicolumn{2}{|c|}{ PASI Score $e^{a, b, d}$} \\
\hline & $\begin{array}{l}\text { No. of } \\
\text { Patients }\end{array}$ & $\mathrm{OR}(\mathrm{Cl})$ & $\begin{array}{l}\text { No. of } \\
\text { Patients }\end{array}$ & $\mathrm{OR}(\mathrm{Cl})$ & $\begin{array}{l}\text { No. of } \\
\text { Patients }\end{array}$ & Effect (SD) & $\begin{array}{l}\text { No. of } \\
\text { Patients }\end{array}$ & Effect (SD) \\
\hline Methotrexate & 135 & 1 [Reference] & 36 & 1 [Reference] & 135 & 0 [Reference] & 36 & 0 [Reference] \\
\hline Biologic & $42^{e}$ & $2.00(0.98$ to 4.00$)$ & $34^{f}$ & $4.56(2.02$ to 10.27$)$ & $42^{e}$ & $-0.31(-0.56$ to -0.06$)$ & $34^{\mathrm{f}}$ & $-3.13(-4.33$ to -1.94$)$ \\
\hline$P$ Value & & .06 & & $<.001$ & & .02 & & $<.001$ \\
\hline
\end{tabular}

Abbreviations: PASI, Psoriasis Area and Severity Index; PASI75, 75\% or greater improvement in PASI; PGA, Physician Global Assessment.

${ }^{a}$ Methotrexate treatment could have been preceded by other conventional systemics or biologic agents. Treatment with biologics could have been preceded by conventional systemics (including methotrexate) or other biologic agents. However, patients were treated at any one time with a single systemic medication.

b Participating sites provided PASI and/or PGA scores at medication initiation and during at least 1 follow-up visit. Patient numbers are therefore not identical in both groups. The percentage of missing data was less than $10 \%$ at each time point.

c The association between medication and severity scores during follow-up was studied by general estimating equation modeling. Patients who received methotrexate and biologics at different times were included in both treatment groups. Sex, age at treatment start, and disease duration did not influence the results and were therefore not included in the model. Follow-up (months) and psoriasis severity scores at the start of treatment also had an association with

psoriasis severity at some point during 6-month follow-up (eTables 3 and 4 in the Supplement). There was no interaction between follow-up duration and medication. Severity score at the start of treatment refers to the corresponding PASI and/or PGA score at medication initiation.

d Etanercept was the most frequently prescribed biologic (29 [69.0\%]) followed by adalimumab (10 [23.8\%]), ustekinumab (2 [4.8\%]), and infliximab (1 [2.4\%])

e Etanercept was the most frequently prescribed biologic (25 [73.5\%]) followed by adalimumab (5 [14.7\%]) and ustekinumab (4 [11.8\%]).

$\mathrm{f}$ The association between medication and severity scores during follow-up was studied by linear mixed modeling. Patients who received methotrexate and biologics at different times were included in both treatment groups. Sex, age at treatment start, and disease duration did not influence the results and were therefore not included in the model. Follow-up (months) and psoriasis severity scores at the start of treatment also had an association with psoriasis severity through the 6-month follow-up period (eTable 4 in the Supplement). There was no interaction between follow-up duration and medication.

$P=.04)$. Overall, 22 of 187 patients receiving methotrexate and 4 of 71 patients receiving biologics discontinued treatment because of a distinct, nonserious AE thought possibly to be drug related. Among children receiving methotrexate, these AEs most often were liver function test results outside of the reference ranges $(n=5)$, nausea $(n=5)$, fatigue $(n=4)$, and infections $(n=4)$. In children who discontinued biologics, AEs were abdominal discomfort $(n=1)$, vomiting $(n=1)$, fatigue $(\mathrm{n}=1)$, and upper respiratory infection $(\mathrm{n}=1)$.

\section{Discussion}

Data on real-world effectiveness in childhood psoriasis are limited ${ }^{5-7,10}$ and, to our knowledge, only 1 prospective trial compared methotrexate with a biologic (adalimumab). ${ }^{6}$ Our retrospective, real-world study in a large cohort of North American and European children with moderate to severe plaque psoriasis focused on the outcome of treatment and drug survival of methotrexate vs biologics-the 2 most commonly prescribed therapies.

In the 16-week comparative trial of weekly oral methotrexate, 0.1 to $0.4 \mathrm{mg} / \mathrm{kg}$ per week (37 patients), vs every-2weeks adalimumab, $0.8 \mathrm{mg} / \mathrm{kg}$ (38 patients), $60.5 \%$ of the patients receiving adalimumab vs $40.5 \%$ of those receiving methotrexate achieved PGA $0 / 1(P=.08)$ and $57.9 \%$ vs $32.4 \%$ achieved PASI75 $(P=.03){ }^{6}$ These prospective results may have underestimated the efficacy of methotrexate, given the short duration (peak efficacy of methotrexate at 6 months ${ }^{5}$ or even 32-52 weeks of subcutaneous methotrexate in adults ${ }^{24}$ ) and low mean dosages of methotrexate $0.15 \mathrm{mg} / \mathrm{kg}$ per week, which is based on the mean dosage $8.0 \mathrm{mg} /$ week and mean weight of $53 \mathrm{~kg}$; the real-world methotrexate dosage is 0.2 to $0.7 \mathrm{mg} / \mathrm{kg}$ per week at initiation with a taper as tolerated. However, PASI75 was achieved in only $33.3 \%$ of 25 children treated with metho- trexate, 0.2 to $0.4 \mathrm{mg} / \mathrm{kg}$ per week (median dosage, $15 \mathrm{mg}$ / week), for 24 weeks in the daily practice Child-CAPTURE registry. ${ }^{5,25}$ Our study showed a 6 -month PASI75 of $40.0 \%$ with a mean methotrexate dosage of $0.29(0.14) \mathrm{mg} / \mathrm{kg}$ per week (maximum, 0.36 [0.15] mg/kg per week) (Table 2 and Table 3), which is within the recommended guidelines for dosing. ${ }^{25,26}$ While most children were administered oral methotrexate, differences and transitions between the use of oral vs subcutaneous methotrexate were not captured.

The children's responses to etanercept, the most common biologic in our population (52 [73.2\%]) compared well with data from other pediatric etanercept studies. The PGA 0/1 (57.0\%) and PASI75 (69.0\%) scores at week 24 and through 264 weeks of monitoring in a study of etanercept, $0.8 \mathrm{mg} / \mathrm{kg}$ per week, in North American children aged 4 to 17 years with moderate to severe plaque psoriasis and maintained through week 264 were comparable with our findings. ${ }^{7-9}$ Twenty-three children (65.2\%) aged 4 to 17 years in another real-world practice setting study achieved PASI75 at 24 weeks and reported sustained improvement through week $52 .{ }^{27}$

We also studied the pattern of response throughout the 6 months of follow-up. After correction for confounding factors and inclusion of all available follow-up visits, a higher likelihood of achieving PGA 0/1 or PASI75 at some time during the 6 months was shown for biologic-treated patients compared with methotrexate-treated children (Table 3) (PGA 0/1: OR, 2.00; 95\% CI, 0.98-4.00; $P=$.06; PASI75: OR, 4.56; 95\% CI, 2.02-10.27; $P<.001$ ), with greater reductions in absolute PGA and PASI scores.

Among children receiving biologics, 52.1\% were from North America ( $n=37$ ) and $47.9 \%$ were from Europe $(n=34)$, reflecting off-label biologics use in North American patients (data lock before the 2016 US Food and Drug Administration approval) (eTable 1 in the Supplement). Most European children who received biologics switched from methotrexate to biologics (20 
Figure. Drug Survival of Methotrexate $(n=187)$ and Biologic Agents ( $n=71)$ for Pediatric Psoriasis

A Discontinuation overall

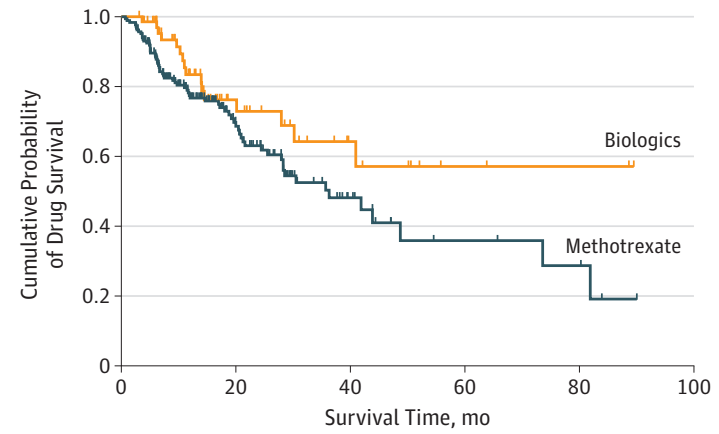

No. at risk

$\begin{array}{llllll}\text { Methotrexate } & 187 & 63 & 16 & 6 & 4\end{array}$ Biologics 71

23

11

B Discontinuation due to ineffectiveness

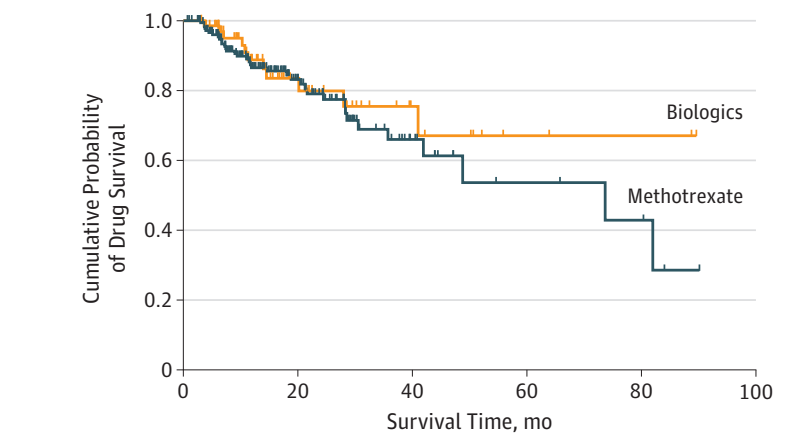

No. at risk

$\begin{array}{llllll}\text { Methotrexate } & 187 & 63 & 18 & 6 & 4\end{array}$

Biologics

11

C Discontinuation due to AES

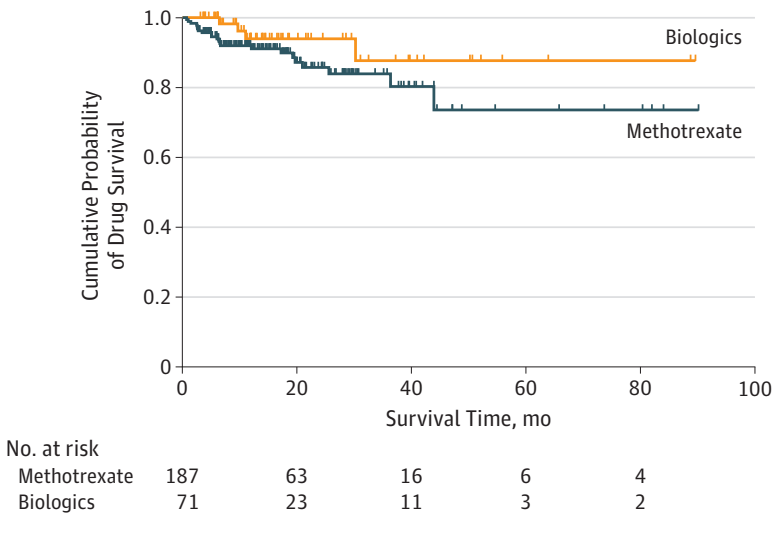

A, Overall survival. B, Drug survival for discontinuation owing to ineffectiveness. C, Drug survival for discontinuation due to an adverse event (AE). Median drug survival time for methotrexate was 36.0 months ([95\% Cl, 23.07-49.53). Median drug survival for biologic agents could not be estimated, as more than $50 \%$ of the patients were still receiving the drug at the end of the study.

of 34 [58.8\%]). In contrast, most children in North America who received biologics had received no previous systemic medication (32 of 37 [86.5\%]), possibly reflecting greater comfort of physicians and parents with the lower perceived risk and venipuncture requirements of biologic use (eTable 2 in the Supplement). Etanercept was US Food and Drug Administration approved for adults in 2004 and the first placebocontrolled study with etanercept in pediatric psoriasis began in 2004. ${ }^{7}$ The availability and greater experience with etanercept among those of us affiliated with North American institutions (A.S.P., D.P.W., I.L.-C., M.M.T., W.L.T., M.H., L.B., E.S., R.A.V., K.H., and K.M.C.) and several of these institutions or investigators were in the pivotal trial (Chicago, San Francisco, San Diego, Toronto, St. Louis), likely contributed to the prescription of biologics in North American children without prior use of methotrexate $(9[27.3 \%])$. Consistently, most treatment episodes began after closure of the etanercept trial (23 [69.7\%]).

To our knowledge, this is the first study to compare drug survival rates and the real-world utility profiles of methotrexate and biologics in pediatric psoriasis. Drug survival is a comprehensive marker of drug effectiveness, safety, and realworld utility, including patient and physician preferences. ${ }^{17}$ The overall 3-year drug survival rates of methotrexate and biologics were $50.3 \%$ and $64.3 \%$, respectively (Figure). Multivariate Cox regression analysis of drug survival corrected for confounders showed that biologics had better overall drug survival than methotrexate (HR, 2.23; 95\% CI, 1.21-4.10; $P=.01$ ). Reasons for drug discontinuation are often a negative event, such as ineffectiveness or the occurrence of AEs. Drug survival of both treatment groups was determined predominantly by discontinuation owing to ineffectiveness. Although ineffectiveness was higher for methotrexate (19.3\%) vs biologics (15.5\%), the difference did not reach statistical significance.

Methotrexate drug survival has been described in 2 other pediatric psoriasis cohorts., ${ }^{5,2}$ The 1-year overall drug survival of methotrexate, described by van Geel et al, ${ }^{5}$ was $72.0 \%$, comparable to our results (77.5\%). Ergun et $\mathrm{al}^{28}$ showed substantially lower methotrexate survival rates, but direct comparison with our data is hindered by differences in event definition and prescription of higher methotrexate doses. Although the percentages of overall drug survival were not stated, calculated 1-year (42.9\%) and 3-year (11.4\%) drug survival rates in another study of biologics in pediatric psoriasis were lower than our results. ${ }^{29}$

\section{Limitations}

Our retrospective analysis was limited by lack of standardization in clinical approach (eg, availability of different treatments, dosages, and treatment schedule) and follow-up visits. In addition, most patients did not have results from both measures (PGA and PASI), introducing possible reporting bias. Although the PGA score was based on recorded information, investigators were asked to adjust data to a single 6-point scale (clear to very severe) vs the use by some of a 5-point scale (clear to severe), which could have underestimated the percentage of very severe disease. An additional limitation in determining drug survival was the failure to specifically collect information about whether physician perception of greater efficacy and safety of biologics induced the change from methotrexate to a biologic. Results of the pivotal studies of etanercept in childhood psoriasis were first reported in 2008 , 
in the middle of the study period, and etanercept became commercially available and on-label shortly thereafter for children in Europe and was available already for adults in the European Union, United States, and Canada. In addition, further stratification to compare biologics was not feasible, given the small numbers.

\section{Conclusions}

The approval of targeted therapies for pediatric psoriasis and publication of results from clinical trials and daily clinical practice cohorts are altering the treatment landscape for patients. Our international, retrospective cohort study appears to support a greater reduction in psoriasis severity from use of biologics compared with methotrexate in a realworld practice setting and showed a longer overall drug survival. In addition to their documented efficacy, biologics are convenient to use, require less monitoring, and are associated with fewer treatment-related toxic effects than conventional agents in children, making them an attractive treatment option. ${ }^{3,4,16}$ Nevertheless, biologics are much more costly than methotrexate, even with the required laboratory monitoring for the latter, and methotrexate still has an important position in the treatment of pediatric psoriasis. Prospective comparative analyses with uniform data recording will be important for future real-world practice studies that complement data from randomized clinical trials.

\section{ARTICLE INFORMATION}

Accepted for Publication: December 13, 2019.

Published Online: February 5, 2020.

doi:10.1001/jamadermatol.2019.4835

Author Affiliations: Department of Dermatology Radboud University, Nijmegen, the Netherlands (Bronckers, Seyger); Department of Dermatology, Northwestern University, Chicago, Illinois (Paller, West); Department of Pediatrics, Northwestern University, Chicago, Illinois (Paller, West); Department of Pediatric Medicine, Dermatology Section, The Hospital for Sick Children, University of Toronto, Toronto, Ontario, Canada (Lara-Corrales); Department of Dermatology, Mayo Clinic, Rochester, Minnesota (Tollefson); Department of Dermatology, Rady Children's Hospital San Diego, University of California, San Diego (Tom); Department of Pediatrics, Rady Children's Hospital San Diego, University of California, San Diego (Tom); Department of Dermatology, Phoenix Children's Hospital, Phoenix, Arizona (Hogeling); now with the Department of Dermatology, UCLA (University of California, Los Angeles) (Hogeling); Department of Dermatology, University of Massachusetts Medical School, Worcester (Belazarian); Department of Dermatology and Allergy, Herlev-Gentofte Hospital, University of Copenhagen, Copenhagen, Denmark (Zachariae); Department of Dermatology, Hôpital Victor Dupouy Argenteuil, Argenteuil, France (Mahé); Department of Dermatology, St Louis University School of Medicine, St Louis, Missouri (Siegfried); Department of Pediatrics, St Louis University School of Medicine, St Louis, Missouri (Siegfried); Department of Dermatology and Allergy, Charité- Universitätsmedizin, Berlin, Germany (Blume-Peytavi); Department of Dermatology, Heim Pál Children's Hospital, Budapest, Hungary (Szalai): Department of Dermatology, Boston Children's Hospital, Boston, Massachusetts (Vleugels); Department of Dermatology, Medical College of Wisconsin, Milwaukee (Holland); Department of Pediatrics, Medical College of Wisconsin, Milwaukee (Holland); Paediatric Dermatology Department, Nottingham University Hospitals, Nottingham, England (Murphy); Department of Dermatology, Hospital de la Santa Creu i Sant Pau, Barcelona, Spain (Puig); Department of Dermatology, University of California, San Francisco Medical Center, San Francisco (Cordoro); Department of Pediatrics, University of California, San Francisco Medical Center, San Francisco (Cordoro); Department of
Dermatology, Ghent University Hospital, Ghent, Belgium (Lambert); First Department of Pediatrics, Agia Sofia Children's Hospital, University of Athens Medical School, Athens, Greece (Alexopoulos); Psoriasis Center at the Department of Dermatology, University Medical Center Schleswig-Holstein, Campus Kiel, Kiel, Germany (Mrowietz); Department for Health Evidence, Radboud University, Nijmegen, the Netherlands (Kievit).

Author Contributions: Drs Bronckers and Paller contributed equally to this work. Drs Bronckers and Seyger had full access to all the data in the study and take responsibility for the integrity of the data and the accuracy of the data analysis.

Concept and design: Bronckers, Paller, West, Vleugels, Murphy, Alexopoulos, Kievit, Seyger. Acquisition, analysis, or interpretation of data: Bronckers, Lara-Corrales, Tollefson, Tom, Hogeling, Belazarian, Zachariae, Mahé, Siegfried,

Blume-Peytavi, Szalai, Holland, Murphy, Puig, Cordoro, Lambert, Mrowietz, Seyger. Drafting of the manuscript: Bronckers, Paller, Vleugels, Murphy, Alexopoulos, Seyger. Critical revision of the manuscript for important intellectual content: Bronckers, West, Lara-Corrales, Tollefson, Tom, Hogeling, Belazarian, Zachariae, Mahé, Siegfried, Blume-Peytavi, Szalai, Holland, Murphy, Puig, Cordoro, Lambert, Mrowietz, Kievit, Seyger.

Statistical analysis: Bronckers, Vleugels, Kievit. Obtained funding: Seyger.

Administrative, technical, or material support: Bronckers, West, Hogeling, Mahé, Szalai, Seyger. Supervision: Paller, Lara-Corrales, Tollefson, Hogeling, Szalai, Cordoro, Lambert, Seyger.

Conflict of Interest Disclosures: Drs Bronckers, Tollefson, Belazarian, Alexopoulos, and Kievit declare no conflict of interest. Dr Paller reported receiving personal fees for consulting from Amgen, Celgene, Dermira, Eli Lilly, Galderma, Leo, Novartis, Pfizer, and UCB and has been an investigator (without personal compensation) for AbbVie, Amgen, Celgene, Eli Lilly, Janssen, Leo Pharma, and Novartis. Dr West reported having been an investigator without personal compensation for Janssen, Eli Lilly, AbbVie, Novartis, Amgen, Pfizer, and Celgene. Dr Lara-Corrales reported having received personal fees for consulting for Janssen, AbbVie, and Johnson \& Johnson, and as speaker for AbbVie, Novartis, and Amgen, and has been an investigator without personal compensation for Janssen, Eli Lilly, and AbbVie. Dr Tom reported having received personal fees for consulting for
UCB and having been an investigator without personal compensation for Amgen, Celgene, Dermira, Incyte, Janssen, Medimetriks, Pfizer, Promius, and Regeneron. Dr Hogeling reported having been an investigator without personal compensation for Amgen and Celgene. Dr Siegfried reported receiving personal fees as a consultant for Amgen, AbbVie Celgene, Dermira, Eli Lilly, Leo, Novartis, Pfizer, Pierre Fabre, Regeneron, Sanofi, UCB, and Verrica, and has been an investigator without personal compensation for Amgen, Celgene, Eli Lilly, Janssen, Leo Pharma, Novartis, and Regeneron. Dr Blume-Peytavi reported having received personal fees for consultation and has been an investigator without personal compensation for Almirall, Galderma, Johnson \& Johnson, Pierre Fabre, and Leo Pharma. Dr Szalai reported having received personal fees as a consultant for Amgen and Sanofi and been an investigator without personal compensation for AbbVie, Eli Lilly, Galderma, Janssen, Leo Pharma, Novartis, and Pfizer. Dr Vleugels reported having been an investigator without personal compensation for Pfizer. Dr Holland reported having received personal compensation for consulting for Amgen and Pfizer and has been an investigator without personal compensation for Eli Lilly and Regeneron. Dr Murphy reported having been an investigator without compensation for Novartis. Dr Cordoro reported receiving personal fees as a consultand for Celgene. Dr Seyger's institution has been paid for her service as a consultant for AbbVie, Almirall, Boehringer Ingelheim, Janssen, Leo Pharma, Lilly, and Pfizer, as a lecturer for AbbVie, Janssen, Lilly, and Pfizer, and as an investigator for AbbVie, Almirall, Astellas, Janssen, Leo Pharma, Lilly and Pfizer. No other disclosures were reported.

Funding/Support: This study was supported by a grant from the International Psoriasis Council. Dr Tom's salary related to psoriasis research is supported, in part, by Career Development Award K23AR060274 from the National Institutes of Health/National Institute of Arthritis and Musculoskeletal and Skin Diseases.

Role of the Funder/Sponsor: The funding organizations had no role in the design and conduct of the study; collection, management, analysis, and interpretation of the data; preparation, review, or approval of the manuscript; and decision to submit the manuscript for publication.

Group Information: Members of the European Working Group on Pediatric Psoriasis include 
Marieke M. B. Seyger, MD, PhD; Claus Zachariae, MD, DMSc; Emmanuel Mahé, MD, PhD; Ulrike Blume-Peytavi, MD, PhD; Zsuzsanna Szalai, MD, PhD; Ruth Murphy, PhD, MD; Luis Puig, MD, PhD; Jo Lambert, MD, PhD; Alex Alexopoulos, MD, PhD; and Ulrich Mrowietz, MD, PhD. Members of the Psoriasis Investigator Group of the Pediatric Dermatology Research Alliance include Irene Lara-Corrales, MD, MSc; Megha Tollefson, MD; Wynnis L. Tom, MD; Marcia Hogeling, MD; Leah Belazarian, MD; Elaine Siegfried, MD; Ruth Ann Vleugels, MD, MPH; Kristen Holland, MD; Kelly M. Cordoro, MD; and Amy S. Paller, MD, MSc.

Additional Contributions: We thank the Psoriasis Investigator Group of the Pediatric Dermatology Research Alliance and the European Working Group on Pediatric Psoriasis for their involvement and, in particular, Eulalia Baselga, MD, PhD (Department of Dermatology, Hospital de la Santa Creu i Sant Pau, Barcelona, Spain), and Sandra Philipp, MD, PhD (Clinical Research Center for Hair and Skin Science, Department of Dermatology and Allergy, Charité-Universitätsmedizin Berlin, Berlin, Germany), for their careful review of the manuscript. We thank our colleagues, the many students, fellows, research assistants, and faculty who helped to gather data for this study: Nicholas Celano, MD (University of California, San Diego), Jennifer Day, MD (Department of Dermatology, Northwestern University), Scott Elman, MD (Children's Hospital of Boston), Hanna Fadzeyeva, MD (Hospital for Sick Children, Toronto, Canada), Rivka Friedland, MD (Department of Dermatology, Northwestern University), Supriya Immaneni, BS (Department of Dermatology, Northwestern University), Tina Kiguradze, BS (Department of Dermatology, Northwestern University), Doris Greczycho (Charité-Universitäts-Medizin, Berlin, Germany), Maria Hitraya-Low, BS (University of California, San Francisco), Michael Johnson, BS (Phoenix Children's Hospital), Adam Kinzel, BS (Medical College of Wisconsin, Milwaukee), and Georgios Kokolakis, MD (Charité-Universitäts-Medizin, Berlin, Germany), Eszter Pap, MD (Heim Pál Children's Hospital Budapest, Hungary), Stephanie Rangel, PhD (Department of Dermatology, Northwestern University), Sofie De Schepper, MD, PhD (Ghent University Hospital, Ghent, Belgium), Kaspar Torz, MD (University Medical Center Schleswig-Holstein, Kiel, Germany), Klara Veres, MD (Heim Pál Children's Hospital, Budapest, Hungary), and Amanda Winkler, BS (University of Massachusetts, Worcester). We appreciate calculation of the body mass index percentiles by Jonathan Silverberg, MD, PhD, MPH (Department of Dermatology, Northwestern University). None of the acknowledged contributors received compensation for these services.

\section{REFERENCES}

1. Boehncke WH, Schön MP. Psoriasis. Lancet. 2015; 386(9997):983-994.

2. Bronckers IM, Paller AS, van Geel MJ, van de Kerkhof PC, Seyger MM. Psoriasis in children and adolescents. Paediatr Drugs. 2015;17(5):373-384.
3. Eichenfield LF, Paller AS, Tom WL, et al. Pediatric psoriasis. Pediatr Dermatol. 2018;35(2):170-181.

4. Bronckers IMGJ, Seyger MMB, West DP, et al; Psoriasis Investigator Group (PsIG) of the Pediatric Dermatology Research Alliance and the European Working Group on Pediatric Psoriasis (EWGPP). Safety of systemic agents for the treatment of pediatric psoriasis. JAMA Dermatol. 2017;153(): 1147-1157.

5. van Geel MJ, Oostveen AM, Hoppenreijs EP et al. Methotrexate in pediatric plaque-type psoriasis. J Dermatolog Treat. 2015;26(5):406-412.

6. Papp K, Thaçi D, Marcoux D, et al. Efficacy and safety of adalimumab every other week versus methotrexate once weekly in children and adolescents with severe chronic plaque psoriasis. Lancet. 2017;390(10089):40-49.

7. Paller AS, Siegfried EC, Langley RG, et al; Etanercept Pediatric Psoriasis Study Group. Etanercept treatment for children and adolescents with plaque psoriasis. N Engl J Med. 2008;358(3): 241-251.

8. Paller AS, Siegfried EC, Eichenfield LF, et al. Long-term etanercept in pediatric patients with plaque psoriasis. J Am Acad Dermatol. 2010;63(5): 762-768.

9. Paller AS, Siegfried EC, Pariser DM, et al. Long-term safety and efficacy of etanercept in children and adolescents with plaque psoriasis. J Am Acad Dermatol. 2016;74(2):280-7.e1, 3.

10. Landells I, Marano C, Hsu MC, et al. Ustekinumab in adolescent patients age 12 to 17 years with moderate-to-severe plaque psoriasis: results of the randomized phase 3 CADMUS study. J Am Acad Dermatol. 2015;73(4):594-603. doi:10. 1016/j.jaad.2015.07.002

11. Annex 1: summary of product characteristics. http://www.Ema.Europa.Eu/docs/en_gb/document_ library/epar_-_product_information/human/ 000262/wc500027361.pdf. Accessed January 2, 2020.

12. Annex 1: summary of product characteristics. http://www.Ema.Europa.Eu/docs/en_gb/document_ library/epar_-_product_information/human/ 000481/wc500050870.pdf. Accessed January 2, 2020.

13. Annex 1: summary of product characteristics. http://www.Ema.Europa.Eu/docs/en_gb/document library/epar_-_product_information/human/ 000958/wc500058513.pdf. Accessed January 2, 2020.

14. Janssen-cilag. International nv. Stelara (ustekinumab) summary of product information. http://www.Accessdata.Fda.Gov/scripts/sda/ sddetailnavigation.Cfm?Sd=labelingdatabase\&id= 5fc208c3e462360ce053564da8c088b7\& rownum=1. Accessed January 2, 2020.

15. Highlights of prescribing information. http://www.Accessdata.Fda.Gov/drugsatfda_docs/ label/2016/103795s5552lbl.pdf. Accessed January 2, 2020.

16. Dogra $S$, Mahajan R. Biologics in pediatric psoriasis. Expert Opin Drug Saf. 2018;17(1):9-16.
17. van den Reek JMPA, Kievit W, Gniadecki R, et al. Drug survival studies in dermatology. J Invest Dermatol. 2015;135(7):1-5.

18. van den Reek JM, van Lümig PP, Driessen RJ, et al. Determinants of drug survival for etanercept in a long-term daily practice cohort of patients with psoriasis. Br J Dermatol. 2014;170(2):415-424.

19. Warren RB, Smith $\mathrm{CH}$, Yiu ZZN, et al. Differential drug survival of biologic therapies for the treatment of psoriasis. J Invest Dermatol. 2015; 135(11):2632-2640.

20. Iskandar IYK, Warren RB, Lunt M, et al; BADBIR Study Group. Differential drug survival of second-line biologic therapies in patients with psoriasis. J Invest Dermatol. 2018;138(4):775-784.

21. Egeberg A, Ottosen MB, Gniadecki R, et al. Safety, efficacy and drug survival of biologics and biosimilars for moderate-to-severe plaque psoriasis. Br J Dermatol. 2018;178(2):509-519.

22. Gniadecki $R$, Bang $B$, Bryld LE, Iversen $L$, Lasthein S, Skov L. Comparison of long-term drug survival and safety of biologic agents in patients with psoriasis vulgaris. Br J Dermatol. 2015;172(1): 244-252.

23. Mrowietz U, Kragballe K, Reich K, et al. Definition of treatment goals for moderate to severe psoriasis: a European consensus. Arch Dermatol Res. 2011;303(1):1-10.

24. Warren RB, Mrowietz U, von Kiedrowski R, et al. An intensified dosing schedule of subcutaneous methotrexate in patients with moderate to severe plaque-type psoriasis (METOP). Lancet. 2017;389(10068):528-537.

25. Menter A, Cordoro KM, Davis DMR. Joint American Academy of Dermatology-National Psoriasis Foundation guidelines of care for the management and treatment of psoriasis in pediatric patients. J Am Acad Dermatol. 2020;82(1):161-201. 26. Dutch Association of Dermatology. Dutch 3 guidelines on psoriasis. http://www.Nvdv.NI/wpcontent/uploads/2014/08/20190515_definitieveversie-richlijnherziening-psoriasis-2017.Pdf. Published 2017. Accessed January 2, 2020.

27. Di Lernia V, Guarneri C, Stingeni L, et al. Effectiveness of etanercept in children with plaque psoriasis in real practice. J Dermatolog Treat. 2018;29(3):217-219.

28. Ergun T, Seckin Gencosmanoglu D, Alpsoy E, et al. Efficacy, safety and drug survival of conventional agents in pediatric psoriasis. J Dermatol. 2017;44(6):630-634.

29. Phan C, Beauchet A, Burztejn AC, et al; Groupe de Recherche de la Société Française de Dermatologie Pédiatrique; Groupe de Recherche sur le Psoriasis de la Société Française de Dermatologie. Biological treatments for paediatric psoriasis. J Eur Acad Dermatol Venereol. 2019;33(10):1984-1992. 